\title{
Electrospun Scaffolds in Tendons Regeneration: a review
}

\author{
R. Di Gesù̀ ${ }^{1,2}$, G. Amato ${ }^{3}$, R. Gottardi1 $1,2,4$ \\ 1 Ri.Med foundation, Palermo, Italy \\ 2 Center for Cellular and Molecular Engineering, Department of Orthopedic Surgery, University of Pittsburgh, \\ Pittsburgh, USA \\ 3 Dipartimento di Scienze del farmaco, Università degli studi di Catania, Catania, Italy \\ ${ }^{4}$ Department of Pediatrics, Division of Pulmonary Medicine, The Children's Hospital of Philadelphia, Philadelphia, USA
}

\section{CORRESPONDING AUTHOR:}

\section{Roberto Di Gesù}

Center for Cellular and Molecular

Engineering

Department of Orthopedic Surgery

University of Pittsburgh, Pittsburgh, USA

E-mail: robertodigesu@gmail.com

DOI:

10.32098/mltj.04.2019.02

LEVEL OF EVIDENCE: 3

\begin{abstract}
SUMMARY
Tissue engineering (TE) is a growing scientific field that combine bioengineering, life science and clinical sciences. This scientific field represents a valid alternative to treatment of several diseases such as cardiovascular pathologies, osteoarthritis, skin burns, and different traumatic injuries. One of the most useful technique employed to produce valid scaffold for tissue engineering is the electrospinning, that allow to obtain highly customizable nanopatterned meshes. The aim of this review is to give an overview of the currently available literature on electrospun scaffold aimed to regenerate tendons and ligaments using a TE approach.
\end{abstract}

\section{KEY WORDS}

tissue engineering; electrospinning; tendon repair; scaffold; ECM, biomaterials; biocompatible polymers

\section{INTRODUCTION}

Tissue engineering (TE) is a rapidly expanding interdisciplinary field aimed to restore and regenerate diseased tissues to restore their native biological functions. The use of TE is stimulating growing interest, and the global market of TE is estimated to involve about $\$ 11.5$ billion in the next three years (1). This approach combine bioengineering, life science and clinical sciences, and is a valid alternative treatment of various diseases such as cardiovascular pathologies, musculoskeletal disorders, or important skin loss consequents to burns or traumatic events (2-4). The main goal of TE is to overcome the shortcomings of surgical techniques (such as auto- or allo- graft) conducted to restore the tissue integrity after extended damage. For instance, one of the most important limitation in reconstructive autograft surgery is the donor tissue shortage, which mean that only small defect can be repaired using this technique (5). In addition, a donor site morbidity drastically decreases the success rate of autograft, and often cause unaesthetic scarring that negatively impact the patients' life quality (6). Donor tissue shortage and donors site morbidity are sometimes bypassed performing allograft surgery. Howev- er, this strategy attracts a decreasing number of clinicians due to related high cost (7), as well as the frequent rejection phenomena that can affect up to $50 \%$ of the allograft in some kind of surgery (7). In this complex panorama, the use of TE could promote the tissue repair reducing the use of highly invasive surgery. The TE approach is based on the combination of two fundamental elements: a biocompatible scaffold mimicking the features of the extracellular matrix (ECM) of the targeted tissues and living cells (8). A scaffold is a three-dimensional construct made of biocompatible materials able to provide the structural support for cell adhesion and proliferation and promoting the formation of new tissue (9). In particular, this construct is conceived as a temporary structure to be gradually resorbed after reasonable time after implantation $(7,10)$. However, as discussed above, the structural analogy with the ECM is a fundamental feature for a scaffold successfully employable in TE (11). ECM is the natural environment that provide structural support to cells in vivo. Each cytotype produce a different ECM with chemical-physical properties that are characteristic for different kind of tissue (12). ECM also actively provide bioactive cues to the residing cells allowing their 
micro patterned disposition inside a tissue (13). Furthermore, ECM is a microporous environment that allows neovascularisation and new tissue formation by dynamic remodelling (13). In this context, the design of an ECM-like scaffold is aimed to provide enough free space for revascularization to facilitate the formation of new tissue, and to promote the integration with host environment (14). Moreover, the presence of interconnected porous network promote the cells mobility and the diffusion of nutrients (14). The porosity grade should be carefully modulated in order to assure the needed mechanical properties, which are strictly related to the physiological environment which the scaffold is designed for (15). Equally important is the three-dimensional architecture of a scaffold, which should reproduce the conformation of the native ECM to guide the optimal spatial cells disposition (15).

The cellular component is usually composed of cells harvested from autologous biopsy and are combined within scaffold by seeding/embedding maintaining conditions promoting cells proliferation. Furthermore, the scaffold's cellularization is often supported from bioreactors to maintain in vitro fundamental parameters such as oxygen and $\mathrm{CO}_{2}$ level, $\mathrm{pH}$, temperature, humidity and osmotic pressure (16). The cell-laden scaffolds are cultured in vitro for a period of time sufficient to obtain a consistent cell density, and then surgically implanted at the donor site target (17).

\section{TISSUE ENGINEERING FOR TENDONS AND LIGAMENTS REPAIR}

In the last decade TE is gaining growing interest in the repair of tendons and ligaments due to the high clinical incidence of injuries, graving especially over elderly and sports people (7). Is estimated that about 30 million of people undergo annually to tendon/ligament repair procedures, causing an annually expense of over $€ 150$ billion in EU and USA $(18,19)$. At present, surgery is the first-line approach to repair tendons and ligaments injuries, and the most common practice is the reconnection of broken tissue by suturing the extremities (20-23). However, surgery is often invasive, in particular when a long tendon is damaged such as Achilles tendons (24). Moreover, adhesion between tendons and surrounding tissue is a common complication after surgical flexor tendon repair (25). Many techniques have been developed to prevent adhesions such as refinement of suturing techniques, reconstruction of tendon sheath, and controlled early mobilization (25). However, surgery still suffer a high unsuccess rate mainly due to limited tissue's healing process (26-28), and up to $40 \%$ of individuals with a history of ligament injury have been found to have residual complaints interfering with daily living (29). In this complex panorama,
TE appears to be a promising approach to overcome current limitations related to surgery, and could improve the quality of life of people affected from tendons and ligaments diseases, and numerous articles focused on electrospun scaffolds applied to tendon tissue engineering published in the last 10 years $(5,30-32)$ clearly highlight this evidence. However, the fabrication of a scaffold is particularly challenging in a highly demanding environment such as tendons and ligament, where high resistance to mechanical stress such as traction and torsion is required. In fact, the main in vivo role of tendons and ligaments is to transmit inter- and intra-structural forces, as well as to improve the joint stability (20). More in detail, tendons transmit forces from muscle to bone and are subjected to intense and repeated cycle of tension/ relaxation $(20,33)$. Ligaments transmit forces from bone to bone and provide joint stability during normal daily movements $(21,34)$ preventing torsion and hyperextension of the articulation (35). Despite different in vivo role of tendons and ligaments, they have similar anatomical structure. Both are mainly composed of triple-helical collagen type I systematically arranged as fibrils, fibers and fascicles $(20,33,35)$. The collagen fibrils are the fundamental force-transmitting unit of the tendon and are usually oriented in parallel with the bone (33). These substructures are surrounded by a superstructure with supporting function named peritenon. This tissue is made of glycosaminoglycans hierarchically organized in different substructures named epitenon and paratenon (36), and more than $90 \%$ of the dry matter of tendons and ligaments are composed of acellular support tissue $(22,36)$. The anatomic architecture of tendons and ligaments confers them high resistance against traction and torsion during locomotion and physical activities (35). Moreover, tendons and ligaments are vascularized only by peripheral vessels mainly distributed in the support tissues like the paratenon $(33,36)$, and this characteristic cause a slow metabolic activity and limited self-healing capacity (27). In this context, a scaffold valuable to repair tendons and ligaments defect should provide a similar environment to support cell proliferation and spatial distribution. For instance, the engineered construct should be designed to guide the cells alignment aiming to promote the formation of a tissue with similar mechanical properties than the native tissue (37). Moreover, other desirable features are tenoinductivity and tenoconductivity properties, terms that describe the ability to promote cells differentiation and remodeling of new tissue respectively (38). In addition, a gradient architecture is highly desirable to mimic the native anatomy at transition site tendon-bone, tendon-muscle and ligament-bone (39). So far, several technologies were adopted aiming to fabricate engineered scaffold to repair tendons and ligaments. Additive manufacturing (AM), also knew as 
$3 \mathrm{D}$ printing, is one of most promising technology currently employed in TE. After first stereolithography presented by Hull in mid 1980s (39), the evolution of 3D printing experienced an exponential growth, and new techniques were developed aiming to overcome the shortcomings of oldest technologies. Today, several kind of 3D printers based on different operating technologies are employed to fabricate nanopatterned and aligned (40) constructs suitable for TE (41). However, the adequate cellularization of $3 \mathrm{D}$ printed constructs is a challenge still open, and a low cell density is a common shortcoming of scaffolds made of synthetic polymers (42). In this context, bioprinting represent a valid alternative of $3 \mathrm{D}$ printing, and is more suitable to produce scaffolds for TE. More in detail, bioprinting is based on the use of bioink usually composed of hydrogels, and the main advantage is the possibility to employ cell-laden. Intuitively, bioprinted constructs show a drastically increased cell density compared to $3 \mathrm{D}$ printed scaffold made of synthetic polymers, and this feature improve the regenerative potential of the constructs. For instance, Laternser et al. (43) used bioprinting to fabricate a cell-laden musculoskeletal tendonlike scaffold based on gelatin methacrylate bioink. However, although bioprinting has high potential in the development of engineered tendons and ligaments, the main limitation is linked to inadequate mechanical properties of construct made of hydrogels (44). In this context, a valid alternative method for biofabrication of engineered construct mimicking tendons/ligaments anatomy is textile technology such as knitting, braiding, wet spinning, melt spinning, and electrospinning. An example is the work presented by Liu et al. (45), who combined knitted silk scaffold with microporous sponges seeded with human mesenchymal stem cells (hMSCs) to engineer ligaments in vitro. More interesting appear the work conducted by Chen et al. (46), who realized a knitted silk-collagen scaffold cellularized with human embryonic stem cells (hESC) for Achille tendon reconstruction. However, knitting is still ineffective to create construct with tunable properties in different spatial directions (47). For this reason, this technique is mainly employed in TE to produce supporting frameworks to improve mechanical properties of scaffold fabricated with other techniques. More promising appear the braiding approach, in which fibers are braided in different 3D geometrical shapes using specific platforms (48). The mechanical properties of braided fibers are relatively easily tunable respect to knitted fibers, and axial and radial load stress are better supported (44). Freeman et al. (49), achieved a systematic study on a construct for anterior cruciate ligaments (ACL) reconstruction to analyze the correlation of the braiding angle with the stress/strain response. They observed that a decrease of the braiding angle, corresponds to an increase in tensile force. Nonetheless, braiding approach is not without disadvantage. Currently available technologies only allow to produce fibers with diameters up to $20 \mu \mathrm{m}$ and with a low porosity, which may limit cellular adhesion and proliferation. An alternative approach to produce artificial tendon was attempted by Kew et al. (50), who took advantage from wet spinning to produce engineered microfibers composed of type-I collagen organized in a pseudo-fascicle structure. However, this technology is still affected by shortcomings such as limited spinning rate, and low fibers drawing ratio (51), which affects the quality of the fibers obtained. Other approaches were attempted using melt spinning to create a scaffold composed of poly (3-hydroxybutyrate-co-3-hydroxyhexanoate) (PHBHHx) for achille tendon repair in a rat model (52). Nevertheless, recent finding showed that the high operating temperature of melt spinning often interact with the chemical integrity of the material. In addition, the products lack in mechanical properties, and are not suitable to be employed in the TE of tendons and ligaments (51). One of the most promising technique adopted to produce scaffold suitable for tissue engineering is electrospinning (53). Even if this technique was developed and patented by J.F. Cooley in 1900 (54), the term "electrospinning" was introduced by Dr. Reneker and co-workers (55) in the mid 1990s, who described electrospun fibers obtained from an aqueous solution of polyethyleneoxyde (PEO). Electrospinning take advantage from electrostatic forces to spin a polymer solution in a process that lead to solvent evaporation. More in detail, the polymer solution is dispensed from a syringe through a positively charged needle toward a negatively charged collector, where is collected as nanopatterned yarns. Interestingly, the polymer solution assumes different geometries during the process. A cone-shaped geometry is typically observed at the extremity of the needle (Taylor's cone), which is composed of positively charged polymer solution. The apex of Taylor's cone is interrupted from the formation of a disordered and rapid movement of polymer nanofibers (whipping), which travel toward the negatively charged collector. Whipping is a fundamental part of the process and assures solvent evaporation and nanofibers formation (56). Electrospinning in tissue engineering growingly attracted the scientific community in the last 20 years, and over 1200 research articles were published in 2018. This technique has become popular due to its advantages, such as simplicity, efficiency, and the low cost of the experimental set-up (57). Moreover, electrospinning is the unique among textile process able to produce fibers characterized by a nanopatterned architecture. In fact, an electrospun construct is usually composed of fibers with nanometric diameters (up to $100 \mathrm{~nm}$ ), which are dimensionally compa- 
rable to ECM structural proteins (approximately 50-500 $\mathrm{nm})$ (58). This nanometric pattern confers to electrospun construct a high surface to volume ratio, which determine a porous architecture promoting cells adhesion and proliferation (59), and other relevant process such as diffusion of nutrients, waste removal (60), and the develop of vascular network (61). Moreover, electrospinning is endowed with adjustable parameters depending from instrumental set-up (flow rate, applied voltage, distance needle-collector) and from chemical properties of the polymeric solution (polymer concentration, viscosity, solvent volatility) (59), and this high customizability allows to produce non-woven fibers tailored to the different experimental needs. Notably, a relatively easy optimization of the polymeric solution properties is sufficient to fabricate an electrospun solvent-free materials (62). This aspect drastically increases the biocompatibility of electrospun scaffold in comparison with construct produced with more conventional techniques such as solvent-casting (63). Electrospinning also contribute to increase cellularization efficiency, a delicate step in the fabrication of a 3D engineered construct. Cell seeding within porous $3 \mathrm{D}$ scaffolds is particularly challenging in construct in which the pores dimensional distribution is too low or too high. In this cases, cells are unable to reach the inner portions of the construct, and tend to distributes only over the external portion of the scaffold. The result is an insufficient cell density and an inadequate scaffold cellularization (64-67). This issue can be addressed using electrospinning to fabricate nanosized meshes cells-embedded. Interestingly, the low current employed (nanoamperes) in a traditional electrospinning apparatus does not affect the cell viability during the process (68). Moreover, recent findings report as the use of biologically friendly solvents allow to recovery cells from electrospun cell-embedded construct, and this approach can be used to assess a post fabrication cells viability. Following this rationale, Eddaoudi et al. (69) and Townsend-Nicholson et al. (70) produced electrospun scaffold from a cell-laden polymeric solution and evaluated cells viability by flow cytometry and gene chip microarray, reporting no differences between post-treated cells and control 72 $\mathrm{h}$ after the scaffold fabrication.

\section{ELECTROSPINNING AND TENDONS/ LIGAMENTS TISSUE ENGINEERING}

As above described, electrospinning is widely employed in tendons/ligaments tissue engineering to address issues commonly related to surgical reconstructive approaches. Adhesion and inflammation are two undesirable conditions that limits the healing of the damaged tissue and negatively affect the surgery's outcomes (71). To address this issue,
Chen and coworkers (72) investigated the anti-adhesion properties of an electrospun material based on a hyaluronic acid (HA)/polycaprolactone PCL blend. Interestingly, silver nanoparticles were embedded into nanofibers to confer them antibacterial properties. Scaffolds were implanted in a rabbit flexor tendon model and showed encouraging results in alleviating peritendinous adhesion and inflammatory phenomena. A similar approach characterized the study of Liu and colleagues, who fabricated an anti-adhesion electrospun scaffold made of PLLA enriched with dextran glassy nanoparticles (DGNs) loaded with basic fibroblast growth factor (bFGF). Notably, the authors used bFGF due to its stimulating activity toward tendon reparation and reported positive results onto tendons repair in a rat Achille tendon model. Unfortunately, a complete tendon/ligament healing after surgical repair is still limited from other unwelcome process. Fibrosis is the most relevant of these processes, and lead to the formation of scar-tissue at the suturing site, which negatively affect the tissue regeneration and drastically reduce the functionality of the new formed tendon/ ligament (73). The TE approach employed to prevent fibrosis, is focused on the fabrication of cellularized constructs to promote the formation of new specialized tissue tendon/ ligament like. With this aim, both tenocytes and mesenchymal stem cells (MSC) are currently employed. Moreover, in the particular case of tendon/ligament tissue, the choice of the most appropriate material also plays a key role in guiding stem cells differentiation in tenogenic lineage (table I). Usually, a scaffold for tissue regeneration is mainly based on biological components, which the ECM of interest is made of. Following this rationale, Type I Collagen and Elastin are biomaterials widely employed in tendon/ligaments TE (74-76). More in detail, Type I Collagen is broadly considered thanks to its tenoinductive and tenoconductive properties and is often employed to realize monocomponent scaffold $(77,78)$. However, despite its biocompatibility, collagen lacks in mechanical properties, and the use of additional polymers is required to address this issue. Elastin is often employed as structural additional component to increase the elastic properties of monocomponent scaffolds Collagen-based (79). More frequently, silk-fibroin (SF) is employed to improve the mechanical properties of collagen-based scaffolds. SF is attractive because is a natural macromolecular protein composed of amphiphilic block copolymers with a hydrophobic portion, ordered and highly conserved, and a hydrophilic portion, less ordered and relatively more complex (80-82). The presence of these blocks confers to SF high elasticity and toughness (83). Maghdouri-White and coworkers (84) exploited the properties of SF to increase the mechanical properties of a collagen-based scaffold aiming to repair tendon. More in detail, the author 
Table I. Materials most commonly employed to fabricate scaffold for tendons/ligaments tissue engineering.

\begin{tabular}{llll}
\hline POLYMER & CLASS & ADVANTAGES & DISADVANTAGES \\
\hline Type I Collagen & Natural & $\begin{array}{l}\text { Tenoinductivity, } \\
\text { Tenoconductivity (41, 42) }\end{array}$ & $\begin{array}{l}\text { Complexity of the structure, } \\
\text { Poor elastic properties (57) }\end{array}$ \\
\hline Silk Fibroin & Natural & Elasticity, toughness (48) & Expensive, short-term material (121) \\
\hline Poly-glycolic acid (PGA) & Synthetic & High biocompatibility (58) & Low yield elongation rate (71) \\
\hline Poly Lactic Acid (PLLA) & Synthetic & $\begin{array}{l}\text { High biocompatibility (60) } \\
\text { Easily electrospinnable (65) }\end{array}$ & High rigidity, low deformability (43) \\
\hline Polydioxanone (PDS) & Synthetic & Mechanical properties, flexibility (61) & Not easily electrospinnable (105) \\
\hline Polycaprolactone (PCL) & Synthetic & High biocompatibility, not expensive (75) & High hydrophobicity (109) \\
\hline
\end{tabular}

electrospun a SF-Collagen blend enriched with bone morphogenetic protein-13 (BMP-13) to confer chemoattractive properties to the scaffold. Interestingly, constructs promoted cells migration and adhesion over human tenocytes and adipose derived stem cells (ADSC) in vitro and make the route for an innovative approach in tendons/ligaments repair.

Following the same rationale, Kwon et al. (85) fabricated electrospun scaffold composed of a silk-based hollow thread filled with a mixture of collagen/chondroitin-6-sulfate to treat tendon injuries. Scaffolds were then implanted in a tendon defect rabbit model to assess the regenerative properties. The authors report that the construct was effective toward cells migration and orientation, and mechanical properties evaluated ex vivo were comparable to native Achille tendon.

The main role of a scaffold for tendon/ligament TE is to provide a mechanical support until the newly regenerated tendons become mechanically competent. For this reason, beside the use of natural polymers several efforts were accomplished to introduce the use of electrospinnable and biocompatible synthetic polymer, characterized from higher resistance to mechanical stress (86).

This kind of polymers are highly customizable thanks to the presence of pendant functional groups, and this feature ensure optimal intra- and inter-chain entanglement necessary for a successful electrospinning process.

Moreover, a synthetic polymer can be tailored to produce nanopatterned ECM-mimicking materials, composed of heterogeneous matrix characterized by gradients-architecture (87). As demonstrated by Samavedi et al. (88), a heterogenous gradient-matrix is able to improve the osseointegration of ligament grafts by mimicking the ligament-bone (L-B) interface characteristic of the native tissue. The authors fabricated a graded co-electrospun scaffold nHAP-doped made of poly-caprolactone (nHAP-PCL) and poly-ester urethane urea (PUR), with a spatial gradient in nano-hydroxyapatite (nHAP) content (ES scaffold) and subsequently immersed these scaffolds into a simulated body fluid to develop a second mineral gradient (SBF scaffold). The incorporation of a mineral phase like HAP into/onto scaffolds has been shown to influence mesenchymal stem cell behavior including attachment, osteoblastic differentiation and phenotypic maturation. The SEM images show nHAP particles size which have an average diameter around $200 \mathrm{~nm}$ (figure 1a). After treatment with $5 \times \mathrm{SBF}$ (simulated body fluid), the nHAP-PCL (ES) fibers were found to be covered with calcium phosphate mineral layer $(\mathrm{CaP})$. Moreover, the fibers in this nHAP-PCL (SBF) region (figure 1c) were found to be coated with more crystallites than the fibers in the PUR (SBF) region (figure 1d).

The cell metabolic activity was found to be active in all region of both scaffolds, showing an increasing of activity from day 1 to day 7 (figure 2a and $\mathbf{b}$ ). ES scaffold shows a higher cell proliferation at both time points.

Another synthetic polymer considered to produce electrospun scaffold is poly glycolic acid (PGA), an highly biocompatible aliphatic polyester widely employed in tissue engineering characterized by a high molecular weight, property that confers toughness and a high melting point (about 225 ${ }^{\circ} \mathrm{C}$ ) with acceptable mechanical properties (89). However, PGA suffer a short in vivo degradation rate, that is usually included between 2 to 4 weeks (90). Therefore, in the context of the tendon tissue engineering PGA can be useful only in the treatment of small injuries. The PGA is easily electrospinnable into nanostructured matrices with high mechanical properties and fast degradation time (91). The high biocompatibility of PGA was demonstrated in a comparative study conducted by Wagenhäuser and coworkers (92). More in detail, the authors produced a scaffold composed of PGA/PDS (PP-sca) and used a collagen-sponge (Col-spo) as reference (figure 3) construct, aiming to repair tendon employing the tendon in situ regeneration (TSR) technique. Tenoinductive properties of both scaffolds were tested in vitro after seeding with human tendons-derived cells (hTDCs) isolated from the long head of the biceps tendon 


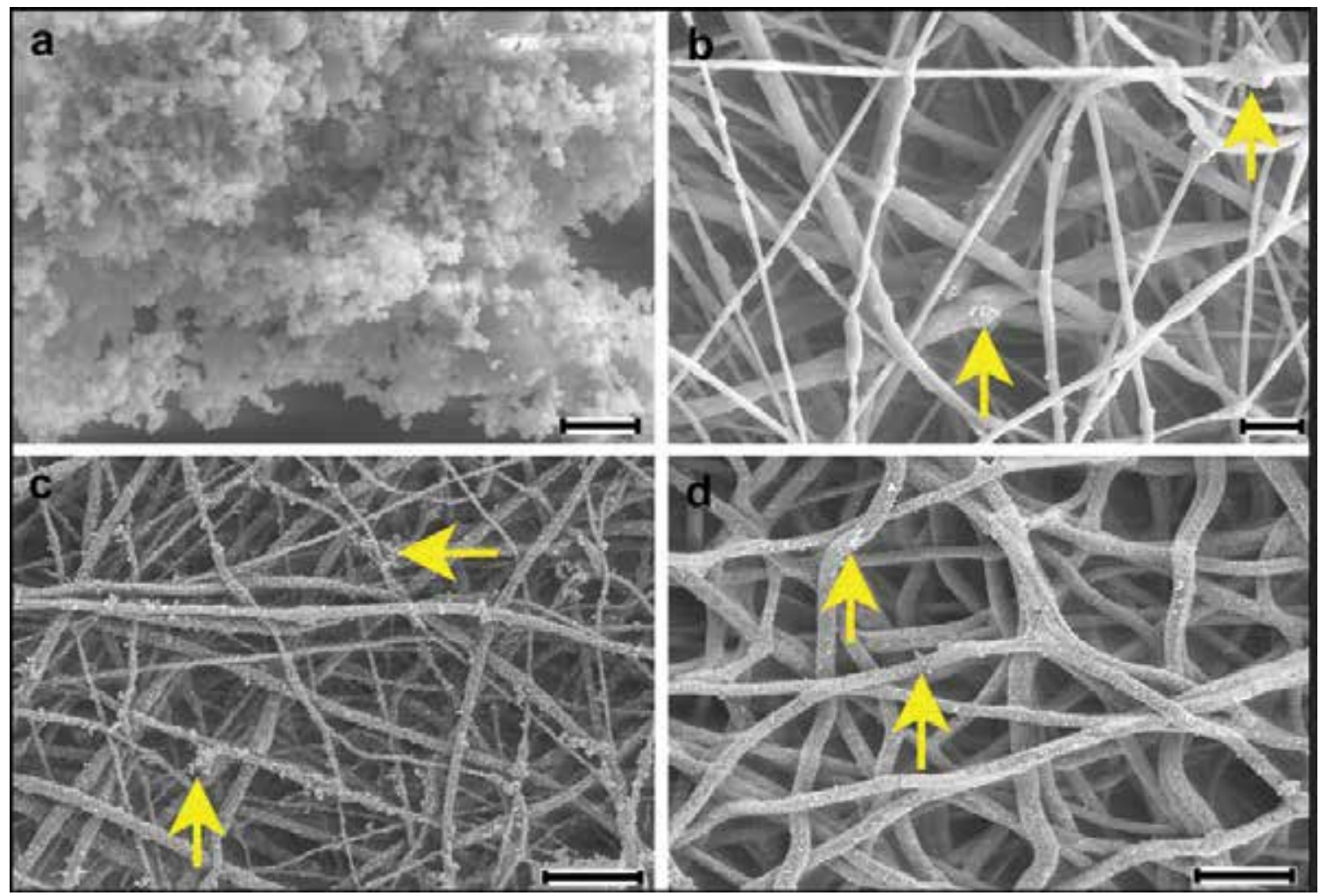

Figure 1. SEM micrographs of: (a) nHAP particles used to fabricate ES scaffold (scale bar: $600 \mathrm{~nm}$ ), (b) nHAP-PCL (ES) region, with arrows showing incorporated $\mathrm{nHAP}$ partially exposed on the surface of fibers (scale bar: $2 \mathrm{~mm}$ ), (c) nHAP-PCL (SBF) region, with arrows showing mineral crystallites (grown from 5 x SBF) decorating fibers (scale bar: $10 \mathrm{~mm}$ ) and (d) PUR (SBF) region, with arrows showing mineral crystallites (grown from $5 \times \mathrm{SBF}$ ) decorating fibers (scale bar: $10 \mathrm{~mm}$ ). Fiber diameters for nHAPPCL and PUR were designed to be significantly different for imaging purposes only.

Reproduced with permission (Samavedi et al., 2012) Copyright 2012, Elsevier.

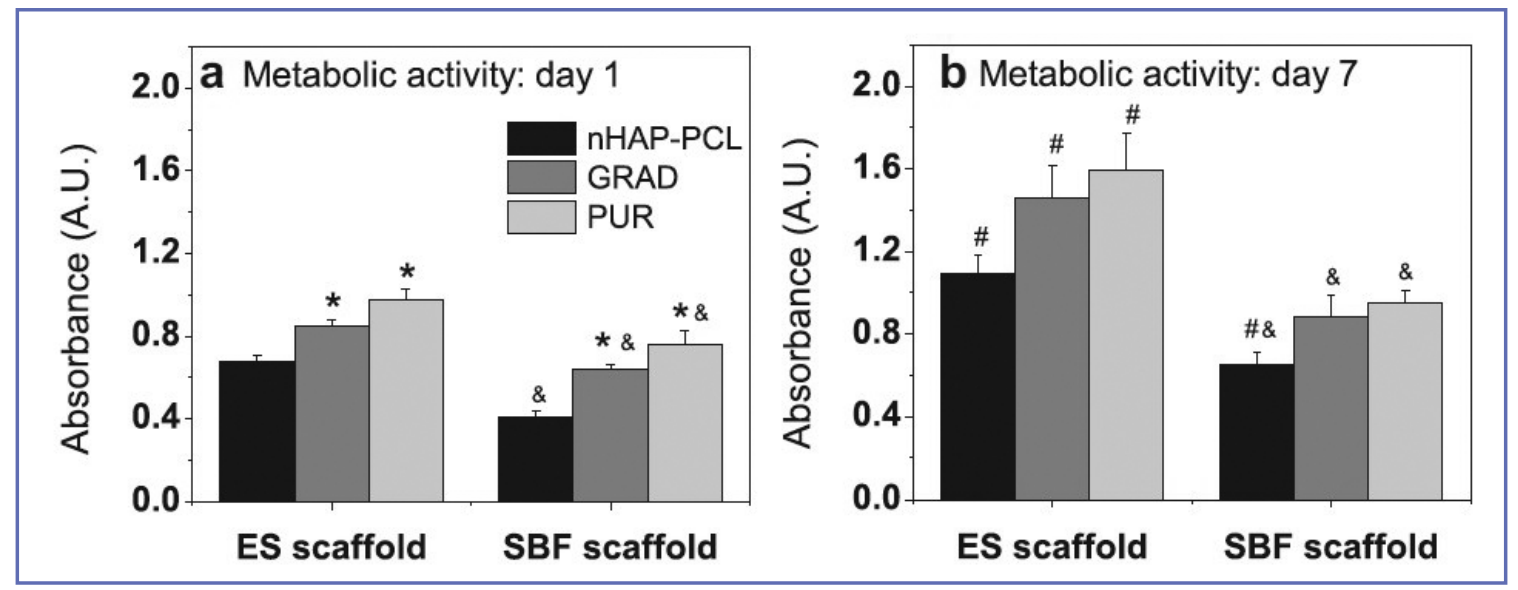

Figure 2. Cell metabolic activity on ES and SBF scaffolds, as determined by an MTT assay. Absorbance values correspond to mean _ standard error of mean for n $1 / 45$ samples. An asterisk indicates statistical significance $(p<0.05)$ compared to the $n$ HAP-PCL region within the same scaffold and time point. An ampersand indicates statistical significance $(p<0.05)$ compared to corresponding regions in the ES scaffold within the same time point. A pound symbol indicates statistical significance ( $p<$ $0.05)$ compared to activity on respective regions at day 1.

Reproduced with permission (Samavedi et al., 2012) Copyright 2012, Elsevier. 

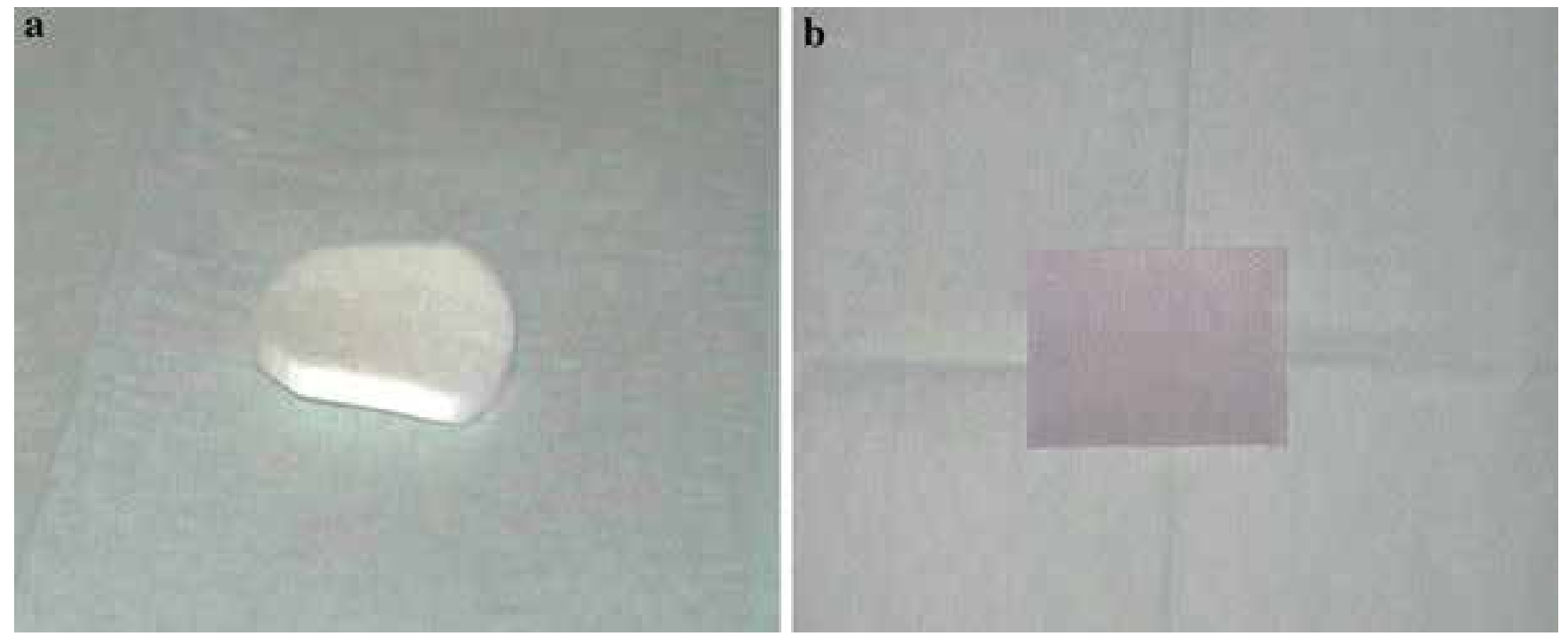

Figure 3. Scaffolds for TTE used for cell seeding experiments in this study. Collagen sponge with a basal strengthening membrane (TissueTek) (a). PGA/PDS scaffold (Ethisorb, Ethicon) (b).

Reproduced with permission (Wagenhäuser et al., 2015) new therapeutic strategies need to be developed. Tendon in situ regeneration (TSR Copyright 2015, Springer).

(LHB), and the results revealed an analogous cell-doubling time. However, if in one hand the PGA scaffold promoted cells adhesion and proliferation, in the other side the tensile strength was not enough to provide an adequate mechanical support for clinical use. For this reason, the interest of scientific community is moving toward the use of more performant electrospinnable synthetic materials.

Polylactic acid (PLA) is one of the most promising biocompatible synthetic polymers suitable in tissue engineering use. The presence of a methyl group in the backbone confers a high hydrophobicity to the PLA, and this chemical feature drastically affect the in vivo degradation time, that is typically of 30-50 weeks (93). The high biocompatibility of the PLA is linked to the chemical nature of its degradation products. In humans, PLA is hydrolyzed in vivo to $\alpha$-hydroxy acid, which are part of the metabolic pathway of the tricarboxylic acid and is easily excreted. Therefore, the PLA degradation products are non-toxic (92) and FDA approved also for contact with biological fluids (94). The overall characteristic of the PLA highly depends on chemical-physical properties such as crystallinity grade, molecular weight $(\mathrm{Mw})$, and stereoisomeric content ${ }^{95}$. In fact, the PLA exist in form of two different stereoisomers, the poly (L-lactide) (PLLA) and the poly (D-lactide) (PDLA), or as the enantiomeric mixture, the poly (DL-lactide) (PDLLA) (96). The PLLA represent the most useful form of the PLA in term of electrospinnability (97). In fact, if PLA show a low crystallinity grade (96), in the counterpart PLLA is about $37 \%$ crystal- line with a $\mathrm{Tm}$ of $175-178{ }^{\circ} \mathrm{C}$ and a $\mathrm{Tg}$ of $60-65^{\circ} \mathrm{C}$ (98) and appear more resistant to the mechanical stress commonly applied during the electrospinning process. These chemical-physical characteristic drastically affect also the in vivo degradation time of the PLLA, that is about of 2 years (99). As shown by Yin et al. (100) the PLLA is a promising material to be employed to produce scaffold able to promote the regeneration of the tendinous tissue. The authors conducted a study onto an electrospun scaffold based on PLLA seeded with human tendon stem/progenitor cells (hTSPCs) aiming to investigate the ability of the construct to promote the hTSPC differentiation. Furthermore, the activity of hTSPCs on aligned nanofibers was investigated and compared with randomly-oriented nanofibers. Results suggested that both aligned and randomly-oriented PLLA scaffolds were able to promote cells adhesion and proliferation, and aligned meshes showed higher mechanical properties and promoted cells orientation (figure 4).

However, we believe that one of the most remarkable study focused on electrospun PLLA meshes aimed to repair tendon injuries was presented by Barber et al. (101). In this work the authors produced braided nanofibrous scaffolds (BNFSs) composed of aligned meshes and seeded with human mesenchymal stem cells (hMSCs). The constructs were then incubated under differentiating stimuli and were able to produce new tendinous tissue. In our point of view, the attractive side of this work is the ability of the PLLA to support the hMSC proliferation and, more interesting- 

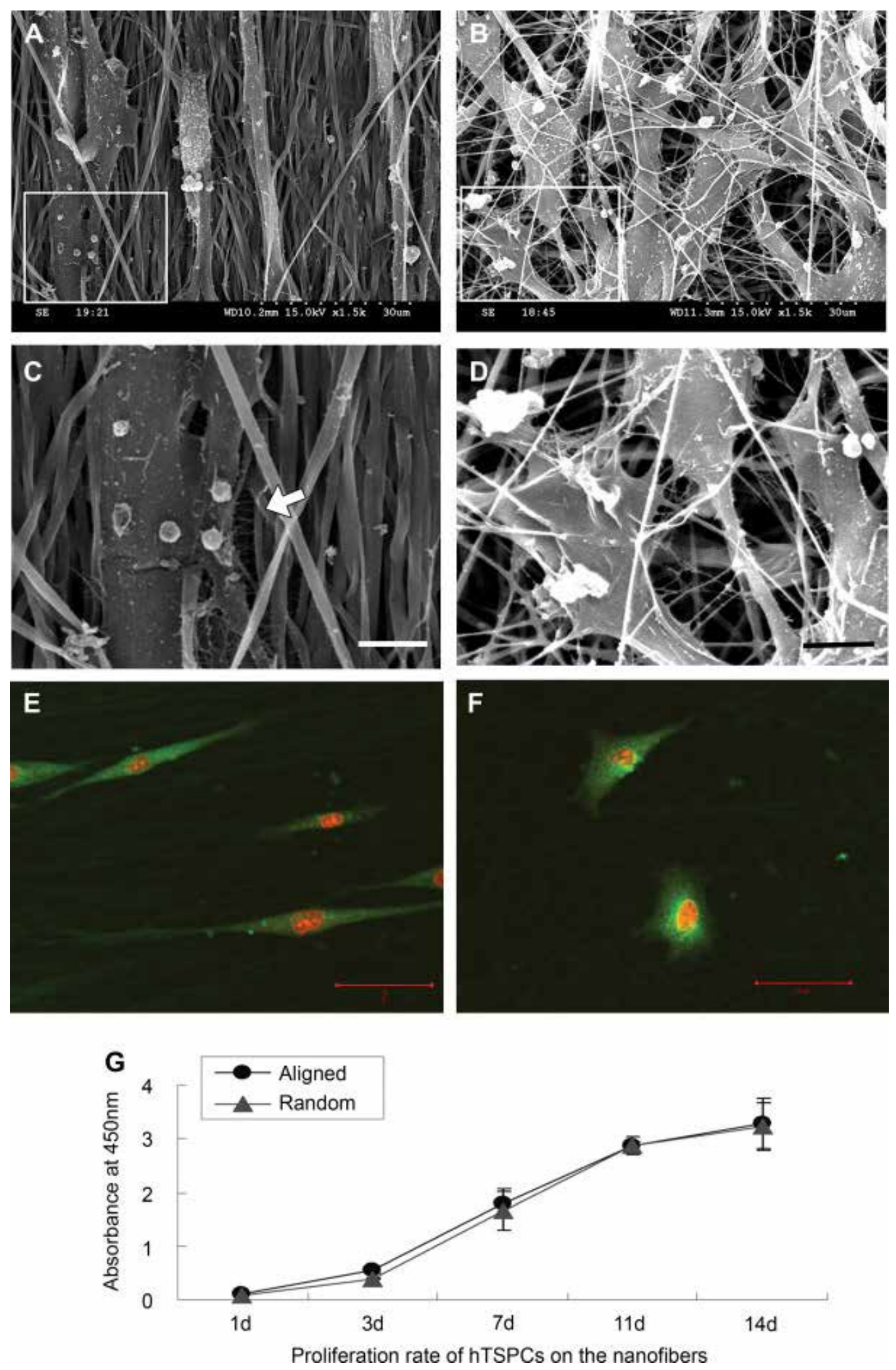

Muscles, Ligaments and Tendons Journal 2019;9 (4)
Figure 4. SEM micrographs $(3000 \mu \mathrm{m})$ of electrospun PLLA with aligned (A) and randomly-oriented (B) fibrous scaffold surface morphology (scale bars $=10 \mathrm{~mm}$ ). SEM micrographies of hTSPCs cultured on the aligned (C) and randomly-oriented (D) scaffold respectively (scale bar = $5 \mu \mathrm{m})$. Confocal micrograph of CFDA-stained elongated hTSPCs on the aligned scaffold $(\mathbf{E})$ and on the randomly-oriented scaffold (F) (scale bar $=50 \mu \mathrm{m}$ ). Loadstrain curves of aligned and randomly-oriented fibrous scaffolds (G). Reproduced with permission (Yin et al., 2010) Copyright 2010, Springer. 
ly, their differentiation into a tenocyte lineage. Beside PLA, polydioxanone (PDO) is another versatile polyester to be used in tendons/ligaments TE. PDO is characterized by high biocompatibility and is widely employed as suturing material in surgical field. It is not a pure polyester but can be better defined as poly (ether-ester), due to an ether bond in the main chain. It is characterized by a high crystallinity degree, that is usually about of $55 \%$, a $\operatorname{Tm} \sim 60^{\circ} \mathrm{C}$, and a $\mathrm{Tg} \sim 0^{\circ} \mathrm{C}$. PDO show a tensile strength $\sim 48 \mathrm{MPa}$ and elongation modulus of about $1500 \mathrm{MPa}$ (93). The inclusion of an ester oxygen in the monomer backbone confer to PDO an excellent flexibility and good mechanical properties (93). PDO was successful electrospun from 2,2,2-trifluoroethanol (TFE) (Padmakumar et al., 2019) (102) or 1,1,1,3,3,3-hexafluoro-2-propanol (HFIP) (103) and employed for tendon tissue engineering (104). One remarkable study was conducted from Hislop et al. (105), that employed PDO to realize an electrospun patch aimed to support rotator cuff tendon self-healing after surgery. Human tendon-derived cells (hTDCs) were seeded into the patch, and cells proliferation was observed within 4 weeks suggested an in vitro tenoinductive effect of the construct. By following a similar rationale Hakimi and co-workers (106) produced a biocompatible composite electrospun patch for improving the physiologic healing rates of rotator cuff repairs. In this case a three-layer scaffold was fabricated by following an architecture PDO/PCL/PDO. External portions of PDO were composed by randomly-oriented microfibers and aligned nanopatterned meshes, with support and cell-attraction function respectively. Central portion of PCL had a mechanical role aimed to separate two PDO portions (figure 5). Composite scaffold was then seeded with hTDCs and proliferation and differentiation were evaluated by in vitro and in vivo tests over rat models, according to the ethical guidelines (126). Results showed good properties in term of tenoinduction and new tendon tissue was able to growth onto implanted scaffold (figure 6).

Another synthetic polyester employed to develop new electrospun material for tendons/ligaments TE is polycaprolactone (PCL) thanks to its relatively low cost compared to the most part of electrospinning biomaterials. Chemically, PCL is a semi-crystalline polyester characterized from five non-polar methylene groups in its repeating unit, and this chemical composition confers to the PCL a high hydrophobicity. As direct consequence, PCL is characterized from a long in vivo degradation time, that is usually between 12 to 24 months (107) and is often employed in tissue engineering as blending agent to modulate the in vivo degradation time of other biomaterials (108). As reported from Orr et al. (109), the PCL represent a promising material to promote the regeneration of damaged tendon tissue. More in detail, the authors fabricated aligned multilayered electrospun nanofibrous scaffolds based on PCL and cellularized with human adipose stem cells (hASCs).

Accurate analyses reported a relevant adhesion and differentiation of human adipose stem cells (hASCs) onto electrospun nanofibers, as well as a significantly relevant increase in the expression of tendon-related genes. Moreover, the construct promoted collagen fibers alignment, and drastically increased tendon-related gene expression. Further studies conducted in vivo in murine models also underlined the noticeable mechanical properties of electrospun PCL scaffolds (110) and their complete integration with the surrounding tendon tissue (111).
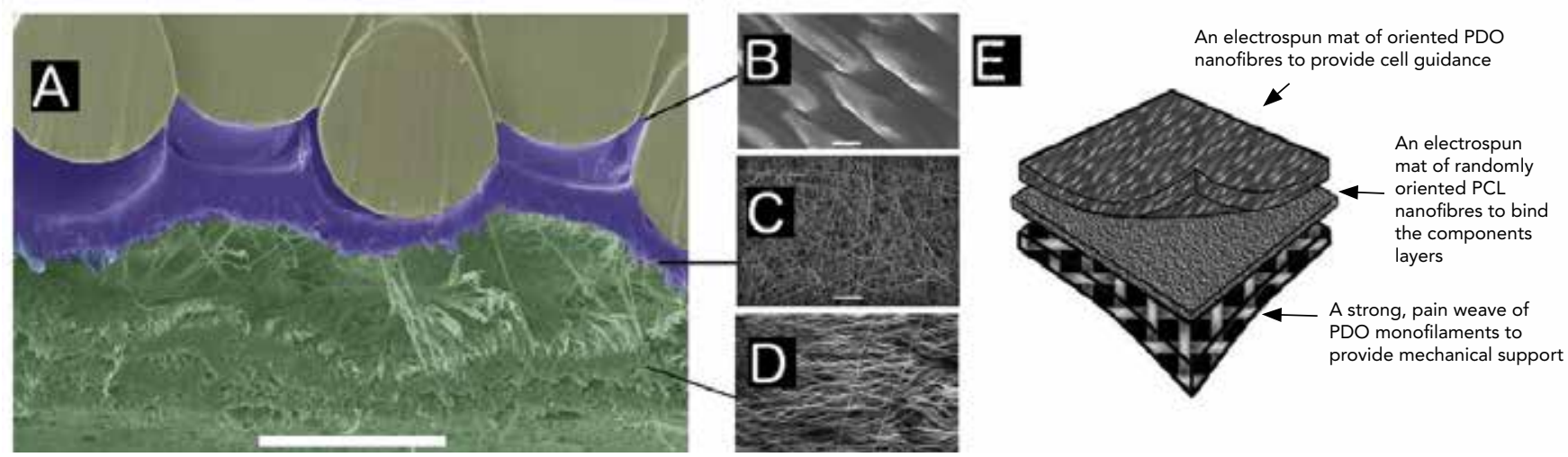

Figure 5. SEM micrographies of cross-section of the layered scaffold (A), of the micropatterned layer (B), of the PCL layer (C) and of the alaigned nanopatterned layer (D). Schematic description of the design rational behind the layered scaffold (E). Scale bars $=100 \mu \mathrm{m}$.

Reproduced with permission (Hakimi et al., 2015)Copyright 2015, Elsevier. 


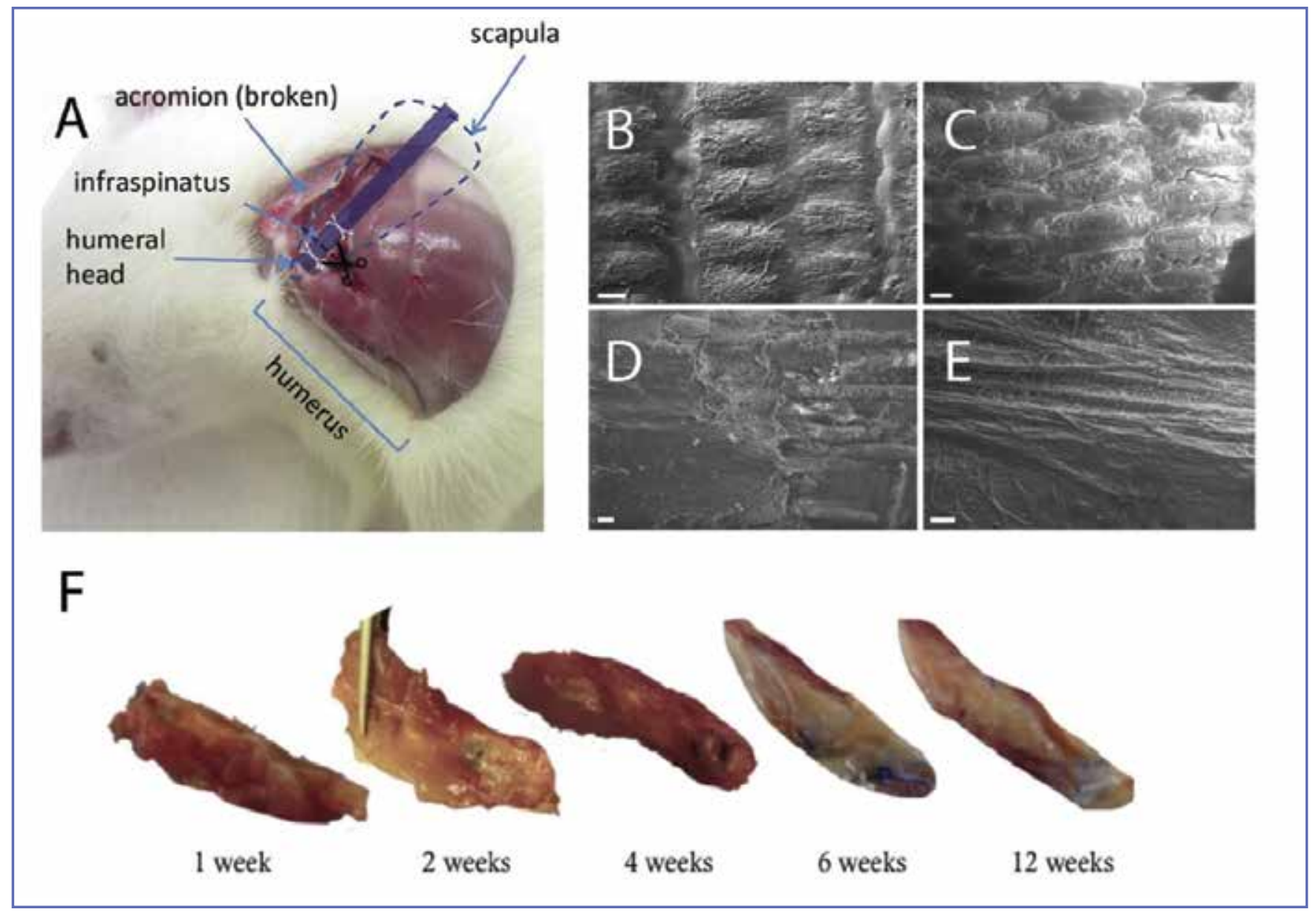

Figure 6. In vivo rat model referring to the rat shoulder (A). SEM micrographies showing new tissue growing onto the scaffold after 2 weeks (B), 4 weeks (C), 6 weeks (D) and 12 weeks (E). The capsule size increased up to 2 weeks in vivo, after which it was reduced and better-defined over 12 weeks $(\mathbf{F})$.

Reproduced with permission (Hakimi et al., 2015). Copyright 2015, Elsevier.

In the context of tendons/ligaments $\mathrm{TE}$, recent tendency is addressed to fabricate electrospun materials composed of polymeric blend, which has the main advantage to improve the overall features of the final product. In particular, the most efficient approach is to employ a mixture of natural/ synthetic polymers in which the natural polymers confer high biocompatibility and good cellular response to the scaffold. At the same time, the synthetic polymers compensate for the lack in mechanical properties which the natural polymers are affected from. Several scientists demonstrated that blended-material showed improved features if compared to single polymeric component. For instance, Sun et al. (112) produced a coelectrospun scaffold based on poly (lactic-co-glycolic acid)/collagen I-polycaprolactone/nanohydroxyapatite (PLGA/Col-PCL/nHA) aimed to repair massive rotator cuff tears (MRCTs). Human fibroblasts and osteoblasts were seeded onto PLGA/Col and PCL/nHA respectively, and the cellular proliferation was sensibly higher in blended scaffold if compared to simple PLGA and PCL nanofibers. A similar approach was followed Xu et al. (113) that fabricated 3D networks of electrospun nanoyarn scaffold composed of PLLA/PCL matrix enriched with Type I collagen. After seeding with Tendon Cells (TDc) they demonstrate that this cytotype maintained native morphology and, in addition, the scaffold promoted cellular proliferation. Other following studies (114) demonstrate the evidence that the same system with aligned fibers, seeded with Tendon-Derived Stem Cells (TDSCs), promoted the regeneration of injured rabbit patellar tendons, and this activity is triggered by mechanical stimulation. By following the same rationale several groups worked on use of SF blended with synthetic polymers for application in TTE. 
Thanks to above described characteristics of the SF, several groups studied and developed tissue engineered based on the employ of this biomaterial (45, 115-123). Analogously, Yang et al. (124) worked to obtain a scaffold suitable for tendon repair, and produced a nanoyarn-reinforced nanofibrous scaffold (NRS) composed by silk fibroin (SF) and poly (1-lactide-co-caprolactone) blends and obtained scaffolds were seeded with bone marrow-derived mesenchymal stem cells (MSCs). Following in vitro studies revealed a sensibly higher proliferation rate inside NRS meshes if compared with correspondent traditional random and aligned electrospun scaffolds.

\section{CONCLUSIONS AND PERSPECTIVES}

Tendons and ligaments healing is a physiologically slow and incomplete process, which is not able to regenerate new functional tissue. Fibrotic tissue usually replace the native one after an injury, compromising the functionality of the affected site. As far, surgery is the approach commonly adopted to repair tendons/ligaments tear and lesion. However, this approach is affected by high failure rates, which may be around at $75 \%$ in some case of rotator cuff repair. In this context, TE represent a promising approach potentially able to promote the regeneration of tendon and ligament tissue-like, and to improve the patients' quality of life. Today several advanced technologies are available to fabricate constructs suitable for tendons/ligaments TE. However, often they are not able to respond to high demanding environment such as tendons and ligaments. For instance, 3D printing still leak in pores consistency and dimensions (125), and in mechanical properties (127). The use of more conventional method like solvent casting, are affected from important disadvantages, mainly linked to

\section{REFERENCES}

1. Kim, K.; Grainger, D. W.; Okano, T. Utah's Cell Sheet Tissue Engineering Center. Regen. Ther. 2019, 11, 2-4. https://doi. org/10.1016/j.reth.2019.03.003.

2. Li, S.; McCarthy, S. Further Investigations on the Hydrolytic Degradation of Poly (DL-Lactide). Biomaterials 1999, 20 (1), 35-44. https://doi.org/10.1016/S0142-9612(97)00226-3.

3. George, S. C. Vascularizing Engineered Tissues for in Vivo and in Vitro Applications. Card. Regen. Repair Biomater. Tissue Eng. 2014, 283-298. https://doi.org/10.1533/978085 7096715.2.283.

4. Ko, H.; Milthorpe, B.; McFarland, C. Engineering Thick Tissues - the Vascularisation Problem. Eur. Cells Mater. 2007, 14, 1-19. https://doi.org/10.22203/eCM.v014a01.

5. Agarwal, S.; Wendorff, J. H.; Greiner, A. Use of Electrospinning Technique for Biomedical Applications. Poly- the presence of organic solvent residues, and to the difficulty in molecules incorporation. Textile technologies appear be more indicated to reproduce anisotropic architecture of tendons and ligaments. Nevertheless, textile methodologies such as braiding or knitting are affected by important drawback such as limited spinning rate, low fibers drawing ratio (51), and low customizability. To date, electrospinning is the most adequate technique to produce a construct mimicking the complex tendons/ligaments architecture. Electrospun nanofibers are characterized from a nanopatterned architecture reproducing tendons/ligaments ECM. Moreover, the possibility to fabricate aligned constructs, positively affect the regenerative outcomes, promoting cells adhesion and proliferation. Furthermore, nanopatterned architecture of electrospun construct is characterized from high porosity, which promote the nutrients diffusion toward resident cells. However, several issue should be addressed to promote a clinical translation of electrospun constructs to repair tendons and ligaments. One negative aspect is the difficulty in the control of the pore network, which is still imprecise and unpredictable. Moreover, the low yield of the electrospinning process negatively impact the pathway toward an industrial scalability.

\section{AKNOWLEDGMENTS}

The authors gratefully thank Ri. Med foundation and the Center for Cellular and Molecular Engineering of the Department of Orthopaedic Surgery of the University of Pittsburgh.

\section{CONFLICT OF INTERESTS}

The authors declare no conflicts of interests. mer (Guildf). 2008, 49 (26), 5603-5621. https://doi. org/10.1016/j.polymer.2008.09.014.

6. Lee, D.; Kim, Y. S.; Roh, T. S.; Yun, I. S.; Hospital, G. S. Cryptotia Recurrence Lowering. 2019.

7. Rowland, R.; Colello, M.; Wyland, D. J. Osteochondral Autograft Transfer Procedure: Arthroscopic Technique and Technical Pearls. Artbrosc. Tech. 2019. https://doi.org/10.1016/j. eats.2019.03.006.

8. Langer, R.; Tirrell, D. A. Designing Materials for Biology and Medicine. Nature 2004, 428 (6982), 487-492. https://doi. org/10.1038/nature02388.

9. Chan, B. P.; Leong, K. W. Scaffolding in Tissue Engineering: General Approaches and Tissue-Specific Considerations. Eur. Spine J. 2008, 17 (SUPPL. 4). https://doi.org/10.1007/ s00586-008-0745-3. 
10. Truby, R. L.; Lewis, J. A. Printing Soft Matter in Three Dimensions. Nature 2016, 540 (7633), 371-378. https://doi. org/10.1038/nature21003.

11. Badylak, S. F. Xenogeneic Extracellular Matrix as a Scaffold for Tissue Reconstruction. Transpl. Immunol. 2004, 12 (3-4), 367-377. https://doi.org/10.1016/j.trim.2003.12.016.

12. Chew, S. Y.; Mi, R.; Hoke, A.; Leong, K. W. The Effect of the Alignment of Electrospun Fibrous Scaffolds on Schwann Cell Maturation. Biomaterials 2008, 29 (6), 653-661. https:// doi.org/10.1016/j.biomaterials.2007.10.025.

13. Yim, E. K. F.; Reano, R. M.; Pang, S. W.; Yee, A. F.; Chen, C. S.; Leong, K. W. Nanopattern-Induced Changes in Morphology and Motility of Smooth Muscle Cells. Biomaterials 2005, 26 (26), 5405-5413. https://doi.org/10.1016/j.biomaterials.2005.01.058.

14. Tozzi, G.; De Mori, A.; Oliveira, A.; Roldo, M. Composite Hydrogels for Bone Regeneration. Materials (Basel). 2016, 9 (4), 1-24. https://doi.org/10.3390/ma9040267.

15. Wang, Y. F.; Barrera, C. M.; Dauer, E. A.; Gu, W.; Andreopoulos, F.; Huang, C. Y. C. Systematic Characterization of Porosity and Mass Transport and Mechanical Properties of Porous Polyurethane Scaffolds. J. Mech. Bebav. Biomed. Mater. 2017, 65 (June 2016), 657-664. https://doi. org/10.1016/j.jmbbm.2016.09.029.

16. Makris, E. A.; Gomoll, A. H.; Malizos, K. N.; Hu, J. C.; Athanasiou, K. A. Repair and Tissue Engineering Techniques for Articular Cartilage. Nat Rev Rheumatol 2015, 11 (1), 21-34. https://doi.org/10.1038/nrrheum.2014.157.Repair.

17. Ibrahim M. El-Sherbiny, M. H. Y. Hydrogel Scaffolds for Tissue Engineering: Progress and Challenges. Glob. Cardiol. Sci. paractice 2013, 3, 316-342. https://doi.org/10.5339/ gcsp.2013.38.

18. Lomas, A. J.; Ryan, C. N. M.; Sorushanova, A.; Shologu, N.; Sideri, A. I.; Tsioli, V.; Fthenakis, G. C.; Tzora, A.; Skoufos, I.; Quinlan, L. R.; et al. The Past, Present and Future in Scaffold-Based Tendon Treatments. Adv. Drug Deliv. Rev. 2015, 84, 257-277. https://doi.org/10.1016/j.addr.2014.11.022.

19. Gaspar, D.; Spanoudes, K.; Holladay, C.; Pandit, A.; Zeugolis, D. Progress in Cell-Based Therapies for Tendon Repair. Adv. Drug Deliv. Rev. 2015, 84, 240-256. https://doi. org/10.1016/j.addr.2014.11.023.

20. Khanna, A.; Friel, M.; Gougoulias, N.; Longo, U. G.; Maffulli, N. Prevention of Adhesions in Surgery of the Flexor Tendons of the Hand: What Is the Evidence? Br. Med. Bull. 2009, 90 (1), 85-109. https://doi.org/10.1093/bmb/ldp013.

21. Reinhardt, K. R.; Hetsroni, I.; Marx, R. G. Graft Selection for Anterior Cruciate Ligament Reconstruction: A Level I Systematic Review Comparing Failure Rates and Functional Outcomes. Orthop. Clin. North Am. 2010, 41 (2), 249-262. https://doi.org/10.1016/j.ocl.2009.12.009.

22. Moshiri, A.; Oryan, A. Structural and Functional Modulation of Early Healing of Full-Thickness Superficial Digital Flexor Tendon Rupture in Rabbits by Repeated Subcutaneous Administration of Exogenous Human Recombinant Basic Fibroblast Growth Factor. J. Foot Ankle Surg. 2011, 50 (6), 654-662. https://doi.org/10.1053/j.jfas.2011.05.002.

23. Oryan, A.; Moshiri, A.; Meimandiparizi, A. H. Effects of Sodium-Hyaluronate and Glucosamine-Chondroitin Sulfate on Remodeling Stage of Tenotomized Superficial Digital
Flexor Tendon in Rabbits: A Clinical, Histopathological, Ultrastructural, and Biomechanical Study. Connect. Tissue Res. 2011, 52 (4), 329-339. https://doi.org/10.3109/030082 07.2010.531332.

24. Ehrl, D.; Heidekrueger, P. I.; Schmitt, A.; Liska, F.; Ninkovic, M.; Giunta, R.; Broer, P. N. The Anterolateral Thigh Flap for Achilles Tendon Reconstruction: Functional Outcomes. Plast. Reconstr. Surg. 2019, 143 (6), 1772-1783. https://doi. org/10.1097/PRS.0000000000005652.

25. Peterson, W. W.; Manske, P. R.; Dunlap, J.; Horwitz, D. S.; Kahn, B. Effect of Various Methods of Restoring Flexor Sheath Integrity on the Formation of Adhesions after Tendon Injury. J. Hand Surg. Am. 1990, 15 (1), 48-56. https://doi.org/10.1016/S0363-5023(09)91105-4.

26. Oryan, A.; Moshiri, A.; Meimandi-Parizi, A. H. Short and Long Terms Healing of the Experimentally Transverse Sectioned Tendon in Rabbits. Sport. Med. Artbrosc. Rebabil. Ther. Technol. 2012, 4 (1), 1-10. https://doi. org/10.1186/1758-2555-4-14.

27. Oryan, A.; Moshiri, A.; Meimandi Parizi, A. H.; Raayat Jahromi, A. Repeated Administration of Exogenous Sodium-Hyaluronate Improved Tendon Healing in an in Vivo Transection Model. J. Tissue Viability 2012, 21 (3), 88-102. https://doi.org/10.1016/j.jtv.2012.06.002.

28. Oryan, A.; Moshiri, A.; Meimandi-Parizi, A. In Vitro Characterization of a Novel Tissue Engineered Based Hybridized Nano and Micro Structured Collagen Implant and Its in Vivo Role on Tenoinduction, Tenoconduction, Tenogenesis and Tenointegration. J. Mater. Sci. Mater. Med. 2014, 25 (3), 873-897. https://doi.org/10.1007/s10856-013-5110-3.

29. Gerber, J. P.; Williams, G. N.; Scoville, C. R.; Arciero, R. A.; Taylor, D. C. Persistent Disability Associated with Ankle Sprains: A Prospective Examination of an Athletic Population. Foot Ankle Int. 1998, 19 (10), 653-660. https://doi. org/10.1177/107110079801901002.

30. Huang, Z. M.; Zhang, Y. Z.; Kotaki, M.; Ramakrishna, S. A Review on Polymer Nanofibers by Electrospinning and Their Applications in Nanocomposites. Compos. Sci. Technol. 2003, 63 (15), 2223-2253. https://doi.org/10.1016/ S0266-3538(03)00178-7.

31. Sill, T. J.; von Recum, H. A. Electrospinning: Applications in Drug Delivery and Tissue Engineering. Biomaterials 2008, 29 (13), 1989-2006. https://doi.org/10.1016/j. biomaterials.2008.01.011.

32. Bhardwaj, N.; Kundu, S. C. Electrospinning: A Fascinating Fiber Fabrication Technique. Biotechnol. Adv. 2010, 28 (3), 325-347. https://doi.org/10.1016/j.biotechadv. 2010.01.004

33. Sharma, P.; Maffulli, N.Tendon Injury and Tendinopathy:Healing and Repair. J. Bone Jt. Surg. 2005, 87 (1), 187-202. https://doi.org/10.2106/JBJS.D.01850.

34. Duchman, K. R.; Lynch, T. S.; Spindler, K. P. Graft Selection in Anterior Cruciate Ligament Surgery. Clin. Sports Med. 2017, 36 (1), 25-33. https://doi.org/10.3928/0147744720100924-20.

35. Oryan, A.; Moshiri, A.; Meimandi-Parizi, A. Graft Selection in ACL Reconstructive Surgery: Past, Present, and Future. Curr. Orthop. Pract. 2013, 24 (3), 321-333. https://doi. org/10.1097/BCO.0b013e31828b85cb. 
36. Moshiri, A.; Oryan, A. Role of Tissue Engineering in Tendon Reconstructive Surgery and Regenerative Medicine: Current Concepts, Approaches and Concerns. Hard Tissue 2012, 1 (2), 1-11. https://doi.org/10.13172/2050-2303-1-2291.

37. Guang Yang, Benjamin B. Rothrauff, Tuan R.S. Tendon and Ligament Regeneration and Repair: Clinical Relevance and Developmental Paradigm. Birth Defects Res C Embryo Today 2013, 99 (3), 203-222. https://doi.org/doi:10.1002/ bdrc.21041.

38. Meimandi-Parizi, A.; Oryan, A.; Moshiri, A. Role of Tissue Engineered Collagen Based Tridimensional Implant on the Healing Response of the Experimentally Induced Large Achilles Tendon Defect Model in Rabbits: A Long Term Study with High Clinical Relevance. J. Biomed. Sci. 2013, 20 (1), 1. https://doi.org/10.1186/1423-0127-20-28.

39. Miar, S.; Shafiee, A.; Guda, T.; Narayan, R. Additive Manufacturing for Tissue Engineering; 2018. https://doi. org/10.1007/978-3-319-45444-3_2.

40. Kim, W. J.; Kim, M.; Kim, G. H. 3D-Printed Biomimetic Scaffold Simulating Microfibril Muscle Structure. $A d v$. Funct. Mater. 2018, 28 (26), 1-12. https://doi.org/10.1002/ adfm.201800405.

41. Liu, S.; Qin, M.; Hu, C.; Wu, F.; Cui, W.; Jin, T.; Fan, C. Tendon Healing and Anti-Adhesion Properties of Electrospun Fibrous Membranes Containing BFGF Loaded Nanoparticles. Biomaterials 2013, 34 (19), 4690-4701. https://doi.org/10.1016/j.biomaterials.2013.03.026.

42. De Giglio, E.; Bonifacio, M. A.; Ferreira, A. M.; Cometa, S.; Ti, Z. Y.; Stanzione, A.; Dalgarno, K.; Gentile, P. Multi-Compartment Scaffold Fabricated via 3D-Printing as in Vitro Co-Culture Osteogenic Model. Sci. Rep. 2018, 8 (1), 1-13. https://doi.org/10.1038/s41598-018-33472-1.

43. Laternser, S.; Keller, H.; Leupin, O.; Rausch, M.; Graf-Hausner, U.; Rimann, M. A Novel Microplate 3D Bioprinting Platform for the Engineering of Muscle and Tendon Tissues. SLAS Technol. 2018, 23 (6), 599-613. https://doi. org/10.1177/2472630318776594.

44. Li, X.; Yang, Y.; Fan, Y.; Feng, Q.; Cui, F. Z.; Watari, F. Biocomposites Reinforced by Fibers or Tubes as Scaffolds for Tissue Engineering or Regenerative Medicine. J. Biomed. Mater. Res. - Part A 2014, 102 (5), 1580-1594. https://doi. org/10.1002/jbm.a.34801.

45. Liu, H.; Fan, H.; Wang, Y.; Toh, S. L.; Goh, J. C. H. The Interaction between a Combined Knitted Silk Scaffold and Microporous Silk Sponge with Human Mesenchymal Stem Cells for Ligament Tissue Engineering. Biomaterials 2008, 29 (6), 662-674. https://doi.org/10.1016/j.biomaterials.2007.10.035.

46. Chen, J. L.; Yin, Z.; Shen, W. L.; Chen, X.; Heng, B. C.; Zou, X. H.; Ouyang, H. W. Efficacy of HESC-MSCs in Knitted Silk-Collagen Scaffold for Tendon Tissue Engineering and Their Roles. Biomaterials 2010, 31 (36), 9438-9451. https:// doi.org/10.1016/j.biomaterials.2010.08.011.

47. Ali, T.; Iman, Y.; Afsoon, F.; Mahboubeh, N.; Huseyin, A.; Raquel, C.-A.; Grissel, S.; Mario, A.; Mohsen, A.; Nasim, A.; et al. Textile Tissue Engineering: A Path towards Organ Weaving. Front. Bioeng. Biotechnol. 2016, 4 (7), 751-766. https://doi.org/10.3389/conf.fbioe.2016.01.00108.
48. Aibibu, D.; Hild, M.; Cherif, C. An Overview of Braiding Structure in Medical Textile; Elsevier Ltd, 2016. https://doi. org/10.1016/b978-0-08-100407-4.00006-5.

49. Freeman, J. W.; Woods, M. D.; Laurencin, C. T. Tissue Engineering of the Anterior Cruciate Ligament Using a BraidTwist Scaffold Design. J. Biomech. 2007, 40 (9), 2029-2036. https://doi.org/10.1016/j.jbiomech.2006.09.025.

50. Kew, S. J.; Gwynne, J. H.; Enea, D.; Brookes, R.; Rushton, N.; Best, S. M.; Cameron, R. E. Synthetic Collagen Fascicles for the Regeneration of Tendon Tissue. Acta Biomater. 2012, 8 (10), 3723-3731. https://doi.org/10.1016/j. actbio.2012.06.018.

51. Clemons, C. Nanocellulose in Spun Continuous Fibers: A Review and Future Outlook. J. Renew. Mater. 2016, 4 (5), 327-339. https://doi.org/10.7569/JRM.2016.634112.

52. Webb, W. R.; Dale, T. P.; Lomas, A. J.; Zeng, G.; Wimpenny, I.; El Haj, A. J.; Forsyth, N. R.; Chen, G. Q. The Application of Poly(3-Hydroxybutyrate-Co-3-Hydroxyhexanoate) Scaffolds for Tendon Repair in the Rat Model. Biomaterials 2013, 34 (28), 6683-6694. https://doi.org/10.1016/j.biomaterials.2013.05.041.

53. Di Gesú, R.; Merlettini, A.; Gualandi, C.; Letizia Focarete, M. Advances in Multidrug Delivery from Electrospun Nanomaterials. Core-Shell Nanostructures Drug Deliv. Theranostics Challenges, Strateg. Prospect. Nov. Carr. Syst. 2018, 406-430. https://doi.org/10.1016/B978-0-08-102198-9.00014-4.

54. Cooley, J. F. Electrical Method of Dispersing Fluids. 1903, $1-6$.

55. Doshi, J.; Reneker, D. H. Electrospinning Process and Applications of Electrospun Fibers. J. Electrostat. 1995, 35 (2-3), 151-296. https://doi.org/10.1016/0304-3886(95)00041-8.

56. Nowlin, J.; Bismi, M. A.; Delpech, B.; Dumas, P.; Zhou, Y.; Tan, G. Z. Engineering the Hard-Soft Tissue Interface with Random-to-Aligned Nanofiber Scaffolds. Nanobiomedicine 2018, 5, 184954351880353. https://doi. org/10.1177/1849543518803538.

57. Asti, A.; Gioglio, L. Natural and Synthetic Biodegradable Polymers: Different Scaffolds for Cell Expansion and Tissue Formation. Int. J. Artif. Organs 2014, 37 (3), 187-205. https://doi.org/10.530/ijao.5000307.

58. Barnes, C. P.; Sell, S. A.; Boland, E. D.; Simpson, D. G.; Bowlin, G. L. Nanofiber Technology: Designing the next Generation of Tissue Engineering Scaffolds. Adv. Drug Deliv. Rev. 2007, 59 (14), 1413-1433. https://doi.org/10.1016/j. addr.2007.04.022.

59. Rim, N. G.; Shin, C. S.; Shin, H. Current Approaches to Electrospun Nanofibers for Tissue Engineering. Biomed. Mater. 2013, 8 (1). https://doi.org/10.1088/1748-6041/8/1/014102.

60. Rnjak-Kovacina, J.; Weiss, A. S. Increasing the Pore Size of Electrospun Scaffolds. Tissue Eng. Part B Rev. 2011, 17 (5), 365-372. https://doi.org/10.1089/ten.teb.2011.0235.

61. Costa, P. F.; Vaquette, C.; Zhang, Q.; Reis, R. L.; Ivanovski, S.; Hutmacher, D. W. Advanced Tissue Engineering Scaffold Design for Regeneration of the Complex Hierarchical Periodontal Structure. J. Clin. Periodontol. 2014, 41 (3), 283-294. https://doi.org/10.1111/jcpe.12214.

62. D’Amato, A. R.; Bramson, M. T. K.; Corr, D. T.; Puhl, D. L.; Gilbert, R. J.; Johnson, J. Solvent Retention in Electrospun Fibers Affects Scaffold Mechanical Properties. Electrospin- 
ning 2018, 2 (1), 15-28. https://doi.org/10.1515/esp-20180002.

63. Thavornyutikarn, B.; Chantarapanich, N.; Sitthiseripratip, K.; Thouas, G. A.; Chen, Q. Bone Tissue Engineering Scaffolding: Computer-Aided Scaffolding Techniques; 2014; Vol. 3. https://doi.org/10.1007/s40204-014-0026-7.

64. Katja, H.; Shengmao, L.; Liesbeth, T.; Sandra Van, V.; Linxia, G.; Aleksandr, O. Bioink Properties before, during and after 3D Bioprinting. Biofabrication 2016, 8 (3), 32002.

65. Pati, F.; Jang, J.; Ha, D. H.; Won Kim, S.; Rhie, J. W.; Shim, J. H.; Kim, D. H.; Cho, D. W. Printing Three-Dimensional Tissue Analogues with Decellularized Extracellular Matrix Bioink. Nat. Commun. 2014, 5, 1-11. https://doi. org/10.1038/ncomms4935.

66. Markovic, M.; Van Hoorick, J.; Hölzl, K.; Tromayer, M.; Gruber, P.; Nürnberger, S.; Dubruel, P.; Van Vlierberghe, S.; Liska, R.; Ovsianikov, A. Hybrid Tissue Engineering Scaffolds by Combination of Three-Dimensional Printing and Cell Photoencapsulation. J. Nanotechnol. Eng. Med. 2015, 6 (2), 021004. https://doi.org/10.1115/1.4031466.

67. Visser, J.; Melchels, F. P. W.; Jeon, J. E.; Van Bussel, E. M.; Kimpton, L. S.; Byrne, H. M.; Dhert, W. J. A.; Dalton, P. D.; Hutmacher, D. W.; Malda, J. Reinforcement of Hydrogels Using Three-Dimensionally Printed Microfibres. Nat. Commun. 2015, 6, 1-10. https://doi.org/10.1038/ncomms7933.

68. Jayasinghe, S. N. Cell Electrospinning: A Novel Tool for Functionalising Fibres, Scaffolds and Membranes with Living Cells and Other Advanced Materials for Regenerative Biology and Medicine. Analyst 2013, 138 (8), 2215-2223. https://doi.org/10.1039/c3an36599a.

69. Eddaoudi, A.; Townsend-Nicholson, A.; Timms, J. F.; Schorge, S.; Jayasinghe, S. N. Molecular Characterisation of Post-Bio-Electrosprayed Human Brain Astrocytoma Cells. Analyst 2010, 135 (10), 2600-2612. https://doi.org/10.1039/ c0an00213e.

70. Townsend-Nicholson, A.; Jayasinghe, S. N. Cell Electrospinning: A Unique Biotechnique for Encapsulating Living Organisms for Generating Active Biological Microthreads/ Scaffolds. Biomacromolecules 2006, 7 (12), 3364-3369. https://doi.org/10.1021/bm060649h.

71. Li, J.; Feng, X.; Liu, B.; Yu, Y.; Sun, L.; Liu, T.; Wang, Y.; Ding, J.; Chen, X. Polymer Materials for Prevention of Postoperative Adhesion. Acta Biomater. 2017, 61, 21-40. https:// doi.org/10.1016/j.actbio.2017.08.002.

72. Chen, C. H.; Chen, S. H.; Shalumon, K. T.; Chen, J. P. Dual Functional Core-Sheath Electrospun Hyaluronic Acid/ Polycaprolactone Nanofibrous Membranes Embedded with Silver Nanoparticles for Prevention of Peritendinous Adhesion. Acta Biomater. 2015, 26, 225-235. https://doi. org/10.1016/j.actbio.2015.07.041.

73. Li, X.; Chen, Z.; Zhang, H.; Zhuang, Y.; Shen, H.; Chen, Y.; Zhao, Y.; Chen, B.; Xiao, Z.; Dai, J. Aligned Scaffolds with Biomolecular Gradients for Regenerative Medicine. Polymers (Basel). 2019, 11 (2). https://doi.org/10.3390/ polym11020341.

74. Gurumurthy, B.; Griggs, J. A.; Janorkar, A. V. Optimization of Collagen-Elastin-like Polypeptide Composite Tissue Engineering Scaffolds Using Response Surface Methodology. J.
Mech. Behav. Biomed. Mater. 2018, 84, 116-125. https://doi. org/10.1016/j.jmbbm.2018.04.019.

75. Hortensius, R. A.; Ebens, J. H.; Dewey, M. J.; Harley, B. A. C. Incorporation of the Amniotic Membrane as an Immunomodulatory Design Element in Collagen Scaffolds for Tendon Repair. ACS Biomater. Sci. Eng. 2018, 4 (12), $4367-$ 4377. https://doi.org/10.1021/acsbiomaterials.8b01154.

76. Zhu, M.; Tay, M. L.; Callon, K.; Tuari, D.; Zhao, L.; Dray, M.; Zhang, J.; Dalbeth, N.; Munro, J.; Young, S.; et al. Overlay Repair with a Synthetic Collagen Scaffold Improves the Quality of Healing in a Rat Rotator Cuff Repair Model. J. Shoulder Elb. Surg. 2019. https://doi.org/10.1016/j. jse.2018.11.044.

77. Butler, D. L.; Gooch, C.; Kinneberg, K. R. C.; Boivin, G. P.; Galloway, M. T.; Nirmalanandhan, V. S.; Shearn, J. T.; Dyment, N. A.; Juncosa-Melvin, N. The Use of Mesenchymal Stem Cells in Collagen-Based Scaffolds for Tissue-Engineered Repair of Tendons. Nat. Protoc. 2010, 5 (5), 849-863. https://doi.org/10.1038/nprot.2010.14.

78. Kim, B. S.; Kim, E. J.; Choi, J. S.; Jeong, J. H.; Jo, C. H.; Cho, Y. W. Human Collagen-Based Multilayer Scaffolds for Tendon-to-Bone Interface Tissue Engineering. J. Biomed. Mater. Res. - Part A 2014, 102 (11), 4044-4054. https://doi. org/10.1002/jbm.a.35057.

79. Sandri, M.; Filardo, G.; Kon, E.; Panseri, S.; Montesi, M.; Iafisco, M.; Savini, E.; Sprio, S.; Cunha, C.; Giavaresi, G.; et al. Fabrication and Pilot In Vivo Study of a Collagen-BDDGE-Elastin Core-Shell Scaffold for Tendon Regeneration. Front. Bioeng. Biotechnol. 2016, 4 (June), 1-14. https://doi. org/10.3389/fbioe.2016.00052.

80. Altman, G. H.; Diaz, F.; Jakuba, C.; Calabro, T.; Horan, R. L.; Chen, J.; Lu, H.; Richmond, J.; Kaplan, D. L. Silk-Based Biomaterials. Biomaterials 2003, 24 (3), 401-416. https:// doi.org/10.1016/S0142-9612(02)00353-8.

81. Charu Vepari, D. L. K. Silk as a Biomaterial. Prog Polym Sci. 2007, 32 (8-9), 991-1007. https://doi.org/10.1016/j.progpolymsci.2007.05.013.Silk.

82. Hardy, J. G.; Scheibel, T. R. Composite Materials Based on Silk Proteins. Prog. Polym. Sci. 2010, 35 (9), 1093-1115. https://doi.org/10.1016/j.progpolymsci.2010.04.005.

83. Zhang, Q.; Yan, S.; Li, M. Silk Fibroin Based Porous Materials. Materials (Basel). 2009, 2 (4), 2276-2295. https://doi. org/10.3390/ma2042276.

84. Maghdouri-White, Y.; Petrova, S.; Sori, N.; Polk, S.; Wriggers, H.; Ogle, R.; Ogle, R.; Francis, M. Electrospun Silk-Collagen Scaffolds and BMP-13 for Ligament and Tendon Repair and Regeneration. Biomed. Phys. Eng. Express 2018, 4 (2), 25013. https://doi.org/10.1088/2057-1976/aa9c6f.

85. Kwon, S. Y.; Chung, J. W.; Park, H. J.; Jiang, Y. Y.; Park, J. K.; Seo, Y. K. Silk and Collagen Scaffolds for Tendon Reconstruction. Proc. Inst. Mech. Eng. Part H J. Eng. Med. 2014, 228 (4), 388-396. https://doi.org/10.1177/0954411914528890.

86. Lytle, I. F.; Arruda, E. M.; Calve, S.; Brown, D. L.; Grosh, K. Implantation Increases Tensile Strength and Collagen Content of Self-Assembled Tendon Constructs. J. Appl. Physiol. 2010, 108 (4), 875-881. https://doi.org/10.1152/ japplphysiol.00921.2009.

87. Timnak, A.; Gerstenhaber, J. A.; Dong, K.; Har-el, Y.; Lelkes, P. I. Gradient Porous Fibrous Scaffolds: A Novel 
Approach to Improving Cell Penetration in Electrospun Scaffolds. Biomed. Mater. 2018, 13 (6).

88. Samavedi, S.; Guelcher, S. A.; Goldstein, A. S.; Whittington, A. R. Response of Bone Marrow Stromal Cells to Graded Co-Electrospun Scaffolds and Its Implications for Engineering the Ligament-Bone Interface. Biomaterials 2012, 33 (31), 7727-7735. https://doi.org/10.1016/j.biomaterials.2012.07.008.

89. Boland, E. D.; Pawlowski, K. J.; Barnes, C. P.; Simpson, D. G.; Wnek, G. E.; Bowlin, G. L. Electrospinning of Bioresorbable Polymers for Tissue Engineering Scaffolds. Polym. Nanofibers 2006, 918, 14-188. https://doi.org/doi:10.1021/ bk-2006-0918.ch014.

90. Wong W.H., M. J. D. Synthesis and Properties of Biodegradable Polymers Used as Synthetic Matrices for Tissue Engineering. In Synthetic Biodegradable Polymer Scaffolds; 1997; pp 51-82. https://doi.org/10.1007/978-1-4612-4154-6.

91. Boland, E. D.; Wnek, G. E.; Simpson, D. G.; Pawlowski, K. J.; Bowlin, G. L. Tailoring Tissue Engineering Scaffolds Using Electrostatic Processing Techniques: A Study of Poly (Glycolic Acid) Electrospinning. J. Macromol. Sci. Part A Pure Appl. Chem. 2013, No. June, 37-41.

92. Wagenhäuser, M. U.; Pietschmann, M. F.; Docheva, D.; Gülecyüz, M. F.; Jansson, V.; Müller, P. E. Assessment of Essential Characteristics of Two Different Scaffolds for Tendon in Situ Regeneration. Knee Surgery, Sport. Traumatol. Artbrosc. 2015, 23 (4), 1239-1246. https://doi.org/10.1007/s00167013-2820-5.

93. Boland, E. D.; Coleman, B. D.; Barnes, C. P.; Simpson, D. G.; Wnek, G. E.; Bowlin, G. L. Electrospinning Polydioxanone for Biomedical Applications. Acta Biomater. 2005, 1 (1), 115-123. https://doi.org/10.1016/j.actbio.2004.09.003.

94. Gupta, B.; Revagade, N.; Hilborn, J. Poly(Lactic Acid) Fiber: An Overview. Prog. Polym. Sci. 2007, 32 (4), 455-482. https://doi.org/10.1016/j.progpolymsci.2007.01.005.

95. Janorkar, A. V.; Metters, A. T.; Hirt, D. E. Modification of Poly(Lactic Acid) Films: Enhanced Wettability from Surface-Confined Photografting and Increased Degradation Rate Due to an Artifact of the Photografting Process. Macromolecules 2004, 37 (24), 9151-9159. https://doi. org/10.1021/ma049056u.

96. Farah, S.; Anderson, D. G.; Langer, R. Physical and Mechanical Properties of PLA, and Their Functions in Widespread Applications - A Comprehensive Review. Adv. Drug Deliv. Rev. 2016, 107, 367-392. https://doi.org/10.1016/j. addr.2016.06.012.

97. Wojasinski, M.; Faliszewski, K.; Ciach, T. Electrospinning Production of PLLA Fibrous Scaffolds for Tissue Engineering Biomedical Engineering. Biomed. Eng. (NY). 2013, No. June, $1-7$.

98. Wise, D. L.; Trantolo, D. J.; Altobelli, D. E.; Yaszernski, M. J.; Gresser, J. D.; Schwartz, E. R. Encyclopedic Handbook of Biomaterials and Bioengineering; 1995; Vol. 1.

99. J.E. Bergsma, W.C. de Bruijn, F.R. Rozema, R. R. M. B. and G. B. Late Degradation Tissue Response to Poly(L-Lactide) Bone Plates and Screws. Eur. J. Pediatr. Dermatology 1995, $16,25-31$

100. Yin, Z.; Chen, X.; Chen, J. L.; Shen, W. L.; Hieu Nguyen, T. M.; Gao, L.; Ouyang, H. W. The Regulation of Tendon Stem
Cell Differentiation by the Alignment of Nanofibers. Biomaterials 2010, 31 (8), 2163-2175. https://doi.org/10.1016/j. biomaterials.2009.11.083.

101. Barber, J. G.; Handorf, A. M.; Allee, T. J.; Li, W.-J. Braided Nanofibrous Scaffold for Tendon and Ligament Tissue Engineering. Tissue Eng. Part A 2013, 19 (11-12), 1265-1274. https://doi.org/10.1089/ten.tea.2010.0538.

102. Padmakumar, S.; Paul-Prasanth, B.; Pavithran, K.; Vijaykumar, D. K.; Rajanbabu, A.; Sivanarayanan, T. B.; Kadakia, E.; Amiji, M. M.; Nair, S. V.; Menon, D. Long-Term Drug Delivery Using Implantable Electrospun Woven Polymeric Nanotextiles. Nanomedicine Nanotechnology, Biol. Med. 2019, 15 (1), 274-284. https://doi.org/10.1016/j.nano.2018.10.002.

103. Ahmad, I. S.; Blanchy, M.; Mbele, G.; Pidial, L.; Vanneaux, V.; Menasché, P.; Williams, G. R.; Kalfa, D. The Influence of Electrospinning Parameters on Polydioxanone Scaffold Properties. Biomed. Phys. Eng. Express 2018, 4 (2).

104. Hakimi, O.; Murphy, R.; Stachewicz, U.; Hislop, S.; Carr, A. J. An Electrospun Polydioxanone Patch for the Localisation of Biological Therapies during Tendon Repair. Eur. Cells Mater. 2012, 24, 344-357. https://doi.org/10.22203/eCM. v024a25.

105. Hislop, S; Hakimi, O; Dragnevski K; Ng, S. C. A. J. The Degradation of Electrospun Polydioxanone Scaffold Patches. In ORS Annual Meeting; 2012; p 87.

106. Hakimi, O.; Mouthuy, P. A.; Zargar, N.; Lostis, E.; Morrey, M.; Carr, A. A Layered Electrospun and Woven Surgical Scaffold to Enhance Endogenous Tendon Repair. Acta Biomater. 2015, 26, 124-135. https://doi.org/10.1016/j. actbio.2015.08.007.

107. Yoshimoto, H.; Shin, Y. M.; Terai, H.; Vacanti, J. P. A Biodegradable Nanofiber Scaffold by Electrospinning and Its Potential for Bone Tissue Engineering. Biomaterials 2003, 24 (12), 2077-2082. https://doi.org/10.1016/S01429612(02)00635-X.

108. Wang, W.; Park, K. Biomimetic Polymers for In Vivo Drug Delivery. In Bioinspired and Biomimetic Polymer Systems for Drug and Gene Delivery; 2015; pp 109-148. https://doi. org/10.1002/9783527672752.ch5.

109. Orr, S. B.; Chainania, A.; Hippensteela, K. J.; Kishana, A.; Gilchrista, C.; Garriguesa, N. W.; Rucha, D. S.; Guilaka, F.; Littlea, D. Aligned Multilayered Electrospun Scaffolds for Rotator Cuff Tendon Tissue Engineering. Acta Biomater 2015, 24, 117-126. https://doi.org/10.1016/j. molmed.2014.11.008.Mitochondria.

110. Vaquette, C.; Sudheesh Kumar, P. T.; Petcu, E. B.; Ivanovski, S. Combining Electrospinning and Cell Sheet Technology for the Development of a Multiscale Tissue Engineered Ligament Construct (TELC). J. Biomed. Mater. Res. - Part B Appl. Biomater. 2018, 106 (1), 399-409. https://doi.org/10.1002/ jbm.b.33828.

111. Bhaskar, P.; Bosworth, L. A.; Wong, R.; O’brien, M. A.; Kriel, H.; Smit, E.; McGrouther, D. A.; Wong, J. K.; Cartmell, S. H. Cell Response to Sterilized Electrospun Poly( $\varepsilon$-Caprolactone) Scaffolds to Aid Tendon Regeneration in Vivo. J. Biomed. Mater. Res. - Part A 2017, 105 (2), 389-397. https:// doi.org/10.1002/jbm.a.35911.

112. Sun, Y.; Han, F.; Zhang, P.; Zhi, Y.; Yang, J.; Yao, X.; Wang, H.; Lin, C.; Wen, X.; Chen, J.; et al. A Synthetic Bridging 
Patch of Modified Co-Electrospun Dual Nano-Scaffolds for Massive Rotator Cuff Tear. J. Mater. Chem. B 2016, 4 (45), 7259-7269. https://doi.org/10.1039/C6TB01674J.

113. Xu, Y.; Wu, J.; Wang, H.; Li, H.; Di, N.; Song, L.; Li, S.; Li, D.; Xiang, Y.; Liu, W.; et al. Fabrication of Electrospun Poly(L-Lactide-Co- $\varepsilon$-Caprolactone)/Collagen Nanoyarn Network as a Novel, Three-Dimensional, Macroporous, Aligned Scaffold for Tendon Tissue Engineering. Tissue Eng. Part C Methods 2013, 19 (12), 925-936. https://doi. org/10.1089/ten.tec.2012.0328.

114. Xu, Y.; Dong, S.; Zhou, Q.; Mo, X.; Song, L.; Hou, T.; Wu, J.; Li, S.; Li, Y.; Li, P.; et al. The Effect of Mechanical Stimulation on the Maturation of TDSCs-Poly(L-Lactide-Coe-Caprolactone)/Collagen Scaffold Constructs for Tendon Tissue Engineering. Biomaterials 2014, 35 (9), 2760-2772. https://doi.org/10.1016/j.biomaterials.2013.12.042.

115. Altman, G. H.; Lu, H. H.; Horan, R. L.; Calabro, T.; Ryder, D.; Kaplan, D. L.; Stark, P.; Martin, I.; Richmond, J. C.; Vunjak-Novakovic, G. Advanced Bioreactor with Controlled Application of Multi-Dimensional Strain For Tissue Engineering. J. Biomech. Eng. 2002, 124 (6), 742. https://doi. org/10.1115/1.1519280.

116. Chen, J.; Altman, G. H.; Karageorgiou, V.; Horan, R.; Collette, A.; Volloch, V.; Colabro, T.; Kaplan, D. L. Human Bone Marrow Stromal Cell and Ligament Fibroblast Responses on RGD-Modified Silk Fibers. J. Biomed. Mater. Res. - Part A 2003, 67 (2), 559-570. https://doi.org/10.1002/ jbm.a.10120.

117. Chen, X.; Qi, Y. Y.; Wang, L. L.; Yin, Z.; Yin, G. L.; Zou, X. H.; Ouyang, H. W. Ligament Regeneration Using a Knitted Silk Scaffold Combined with Collagen Matrix. Biomaterials 2008, 29 (27), 3683-3692. https://doi.org/10.1016/j.biomaterials.2008.05.017.

118. Toh, S. L.; Teh, T. K. H.; Vallaya, S.; Goh, J. C. H. Novel Silk Scaffolds for Ligament Tissue Engineering Applications. Key Eng. Mater. 2006, 326-328 I, 727-730. https://doi. org/10.1016/j.bmcl.2015.07.084.

119. Seo, Y. K.; Choi, G. M.; Kwon, S. Y.; Lee, H. S.; Park, Y. S.; Song, K. Y.; Kim, Y. J.; Park, J. K. The Biocompatibility of Silk Scaffold for Tissue Engineered Ligaments. Key Eng. Mater. 2007, 342-343, 73-76. https://doi.org/10.4028/www. scientific.net/KEM.342-343.73.

120. Fan, H.; Liu, H.; Wong, E. J. W.; Toh, S. L.; Goh, J. C. H. In Vivo Study of Anterior Cruciate Ligament Regeneration Using Mesenchymal Stem Cells and Silk Scaffold. Biomaterials 2008, 29 (23), 3324-3337. https://doi.org/10.1016/j. biomaterials.2008.04.012.

121. Fan, H.; Liu, H.; Toh, S. L.; Goh, J. C. H. Anterior Cruciate Ligament Regeneration Using Mesenchymal Stem Cells and Silk Scaffold in Large Animal Model. Biomaterials 2009, 30 (28), 4967-4977. https://doi.org/10.1016/j.biomaterials.2009.05.048.

122. Liu, H.; Fan, H.; Toh, S. L.; Goh, J. C. H. A Comparison of Rabbit Mesenchymal Stem Cells and Anterior Cruciate Ligament Fibroblasts Responses on Combined Silk Scaffolds. Biomaterials 2008, 29 (10), 1443-1453. https://doi. org/10.1016/j.biomaterials.2007.11.023.

123. Horan, R. L.; Toponarski, I.; Boepple, H. E.; Weitzel, P. P.; Richmond, J. C.; Altman, G. H. Design and Characterization of a Scaffold for Anterior Cruciate Ligament Engineering. J. Knee Surg. 2009, 22 (1), 82-92. https://doi. org/10.1055/s-0030-1247730.

124. Yang, C.; Deng, G.; Chen, W.; Ye, X.; Mo, X. A Novel Electrospun-Aligned Nanoyarn-Reinforced Nanofibrous Scaffold for Tendon Tissue Engineering. Colloids Surfaces B Biointerfaces 2014, 122, 270-276. https://doi.org/10.1016/j. colsurfb.2014.06.061.

125. Chocholata, P.; Kulda, V.; Babuska, V. Fabrication of Scaffolds for Bone-Tissue Regeneration. Materials (Basel). 2019, 12 (4). https://doi.org/10.3390/ma12040568.

126. Padulo J, Oliva F, Frizziero A, Maffulli N. Muscles, Ligaments and Tendons Journal - Basic principles and recommendations in clinical and field Science Research: 2018 update. MLTJ 2018; 8(3): 305 - 307.

127. Di Gesù R., Abhinav A.P., Jacobs I., Gottardi R., 3D printing for tissue engineering in otolaryngology, Connective tissue research (https://doi.org/10.1080/03008207.2019.1 663837) 